\title{
Virtual Prototype Modeling and Simulating Analysis of Lotus Root Slicing Machine Based on ADAMS
}

\author{
Jianping $\mathrm{Hu}$, Jing Wang, Yinsa Huang, and Enzhu Wei \\ Institute of Agricultural Engineering of Jiangsu University, Zhenjiang City, 212013, \\ Jiangsu China \\ hujp@ujs.edu.cn
}

\begin{abstract}
Based on the lotus root slicing machine of crank-slider style designed by the authors, the virtual prototype model of slicing machine has been established by the software of PRO/E, and the kinematics and dynamics performances of the slicing machine were studied by utilizing ADAMS. At the same time, analyses were made on the changes of the cutting velocity and acceleration of blade, the force condition of cutting, the vibration condition of workbench based on the cutting force of sliced lotus root and inertia force of mechanism. The results show that the optimum period for the cutting was $0.15 \mathrm{~s} \sim 0.25 \mathrm{~s}$; The horizontal component with support reaction of crankshaft bearing was the major factor that affected the system vibration; The vertical component of the force acting on blade during the cutting was the main cause to lead the bevel edge in the piece of lotus root. The research results can provide a reference for the optimized parameters of the cutting mechanism of lotus root.
\end{abstract}

Keywords: Lotus root, Slicing machine, Virtual prototype, Simulating.

\section{Introduction}

The lotus root is a kind of vegetable with hollow inside, containing high rate of water and starch. At present, a large number of lotus food exported to Japan, Korea and other countries by the form of semi-finished lotus slice. The processing of the freshcut lotus slice mainly depends on manpower result in the high labor intensity, low efficiency and poor security. Therefore a crank-slider style lotus root cutting machine was designed to improve the efficiency and reduce labor intensity of Lotus root slicing[1],[6]. In this paper, in order to solve the problems in the designed lotus root slice machine, such as the large vibration, the unsatisfied cutting smoothness, effect hypotenuses and other problem, the virtual prototyping technology was used to establish the parametric model of the original physical prototype, Kinematic and dynamic simulation was carried on to identify the main factors that impact on the working performance, and then optimized the system design.

\section{Virtual Prototype Modeling of the Lotus Root Slicing Machine}

\subsection{Structure and Working Principle of the Cutting Mechanism}

The slicing machine of lotus root adopted crank-slider type cutting mechanism, which is shown in Figure 1. The slicer is installed on the slider. The lotus root is placed in 
the feeding guide. The horizontal cutting movement of the dicer is driven by the crank. According to the diameter size of the Lotus root, the parameters of the cutting mechanism are designed as follows: the length of the Crank is $115 \mathrm{~mm}$, the length of the linkage is $335 \mathrm{~mm}$, the stroke of the slicer is $230 \mathrm{~mm}$; the total width of the slicer is $830 \mathrm{~mm}$, so that the lotus root in four feeding guides can be cut at one time.

\subsection{Virtual Prototype Modeling of the Slicing Machine}

The 3D solid model design and assembly of parts were completed by using of Pro/E4.0 wildfire version according to the design parameters of the slicing machine, then established the virtual prototyping parameterized model of the Lotus root slicer. Completed the transformations of the 3D solid model by using of the Mechanism/Pro which is dedicated interface module of ADAMS and Pro/E. After the successful transformation of the model, added the constraints of the cutting mechanism and the whole machine in ADAMS, including kinematic pairs and constraints, driving force and the working load, as it is shown in Figure 1. The model contains 23 mobile bodies, 3 revolute joints, 1 translation joint, 19 fixed joints and 1 rotational driver. There are six degrees of freedom in the model.

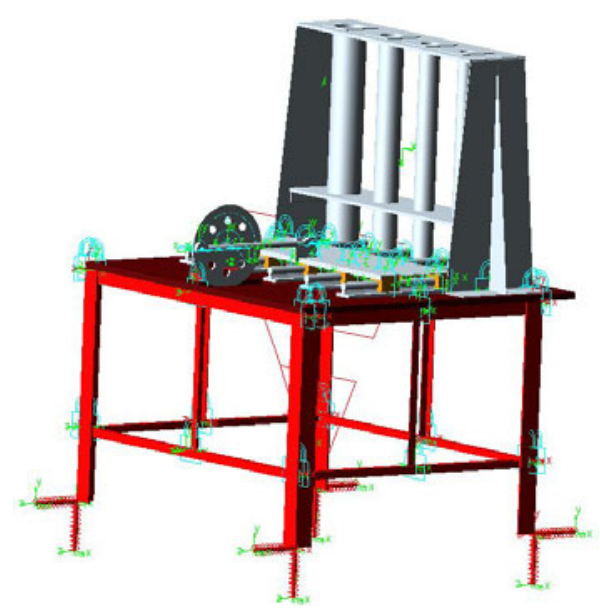

Fig. 1. Virtual prototyping of the lotus root slicing machine

\subsection{Flexible Treatment of the Bench}

In Practical application, it is discovered that the bench vibrated when the slicing knife reciprocating, especially during the high speed cutting the vibration of the working bench is particularly significant. The main reason is that there exists imbalance inertia forces in the cutting mechanism, and the inertia forces effects on the working bench through the kinematic pairs and then to the ground.

As the model imported from Pro/E to ADAMS, all of the model components are defaulted as rigid body, while the bench structure virtually is stiffness and damping. Therefore, in order to improve the accuracy in analyzing the acceleration of the vibration, the working bench should be flexible treated before the vibration analyze. The 
flexible constraints was added by using of the dummy part in the AUTOFELX module in ADAMS [2],[3], then completed the flexible treatment of each angle iron, as shown in Figure 2.

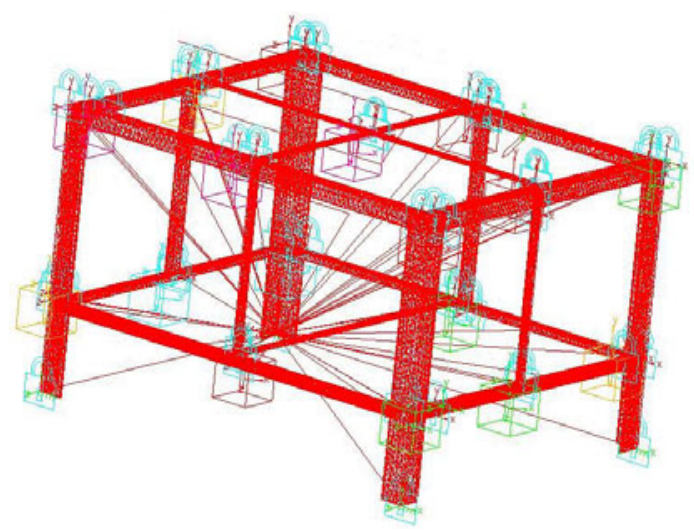

Fig. 2. The flexible body of the bench

\section{Kinematics Simulation of Lotus Root Slicer}

The cutting experiments show that the cutting quality and the breakage of the lotus root slices influenced by the cutting speed and the initial position of cutting point [6]. The change of the displacement, the speed and the acceleration of the slicing knife under different working condition can be found out by kinematics simulation of the cutting mechanism. Provided the reference for optimizing the cutting velocity and the cutting initial point. In the kinematics simulation of the cutting mechanism, the bench was connected onto the ground by fixed joint, merely simulation analyzing the kinematic relation between crank disk, connecting rod and slicing knife of the lotus root slicer [4],[5]. The curves of displacement, velocity and acceleration of the blade centroid under the condition of the crank in the 60 90r/min, as shown in Figure 3, Figure 4 and Figure 5.

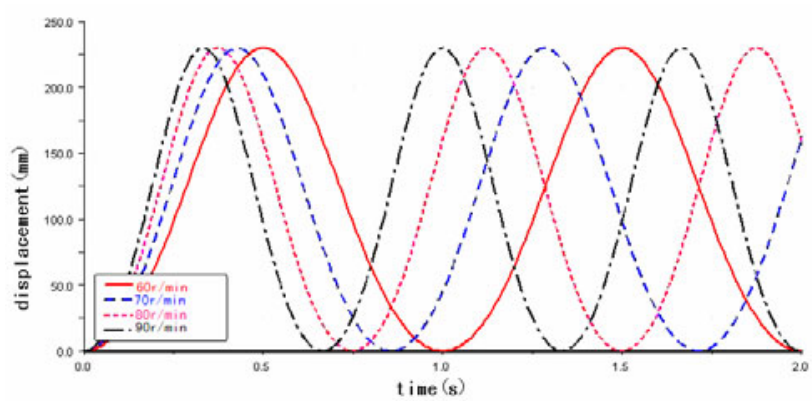

Fig. 3. The displacement curve of centroid of blade at $60 \sim 90 \mathrm{r} / \mathrm{min}$ 
As can be seen from Figure 3, when crank speed in the 60 90r/min, the displacement of the blade centroid has no change in the amplitude, while the movement stroke of the blade expressed that the distance from trough to crest, of which the value was $230 \mathrm{~mm}$, just was two times the length of the crank. It is coincided with the theoretical results.

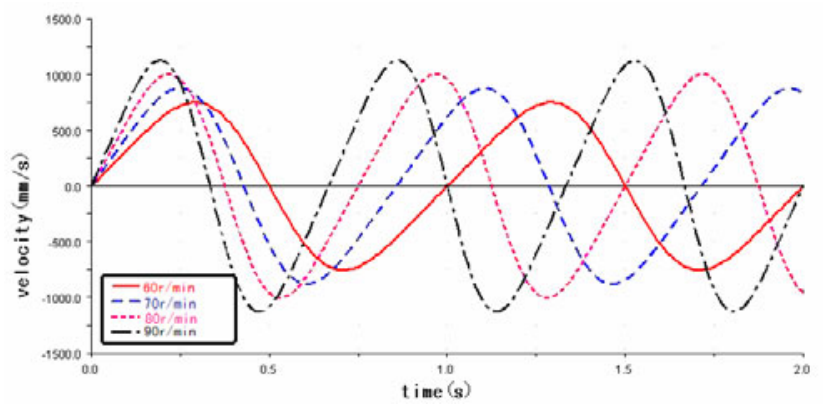

Fig. 4. The velocity curve of centroid of blade at $60 \sim 90 \mathrm{r} / \mathrm{min}$

As can be seen from Figure 4, the velocity of the blade centroid increased with the crank rotational speed increased. Calculated by one cycle, compared the period of time $0.2 \mathrm{~s}$ to $0.3 \mathrm{~s}$ with others, the running rate of the blade centroid was faster. According to the cutting request of the lotus root slice, the blade should have the high speed when cutting, therefore this time section was advantageous to the cutting process.

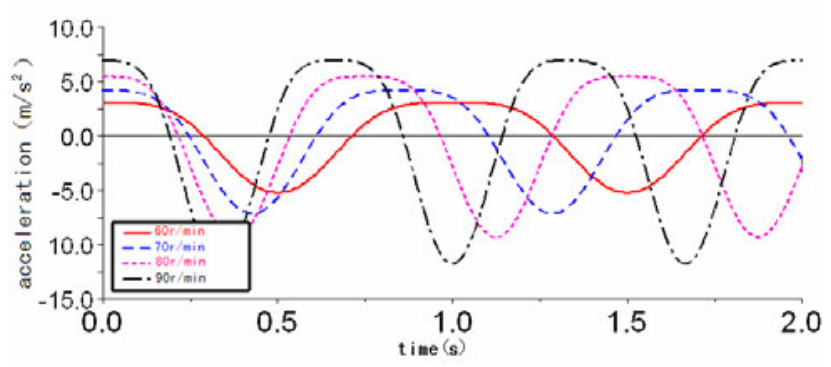

Fig. 5. The acceleration curve of the blade centroid at 60 90r/min

It can be seen from the acceleration curve, Figure 5 that compared the period of time $0.15 \mathrm{~s}$ to $0.3 \mathrm{~s}$ with others, the acceleration value of blade was relatively quite small in the four rotational speed of the crank. As the cutting mechanism was a crankslider, slider fixed with the blade, if the acceleration of the reciprocating components was large, the resulting inertial force was also large, so the period of time when the acceleration values relatively small should be chosen for the lotus root cutting section. In order to improve the cutting quality of lotus root, the period of time $0.15 \mathrm{~s}$ to $0.3 \mathrm{~s}$ was selected for the cutting. 


\section{Dynamics Simulation of the Cutting Mechanism}

Before the simulation, the average cutting resistance was measured by using of WDW30005 type micro-controlled electronic universal testing machine, and the result is $24.8 \mathrm{~N}[1]$. In the dynamic simulation, added the cutting force to the $3 \mathrm{D}$ model of the cutting mechanism by using the STEP function of ADAMS, the cutting force $\mathrm{F}$ = STEP (TIME, 0.25, 0, 0.3, 24.8) +STEP (TIME, 0.45, 0, 0.5, -24.8) [6 9].

\subsection{The Reaction Analysis of Bearing Spider in Crank Place}

According to the characteristics of slider-crank: when the slider for reciprocating motion, the imbalance inertia force of the bodies mainly supported by the crank bearings, so it was necessary to analysis the constraint reaction force at the crank bearings in the mechanism.

The bearing spider reaction force including X, Y two directions, Figure 7, Figure 8 respectively shown the simulation result at the crank rotational speed in the 60 90 r/min. As the reaction force curve of X, Y direction can be seen, the influence that the reaction force of $\mathrm{X}$ direction is much greater than $\mathrm{Y}$ direction to the system, that is, the reaction force of $\mathrm{X}$ direction will be one of the main causes which caused vibration of slicer bench.

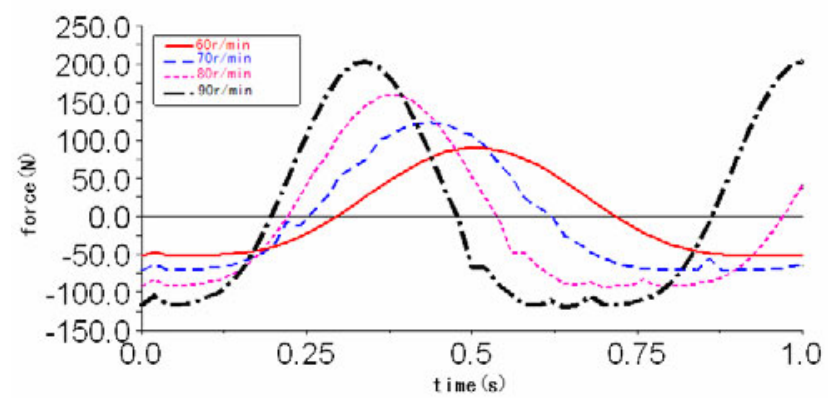

Fig. 6. The reaction of crankshaft bearing on $\mathrm{X}$ axis direction

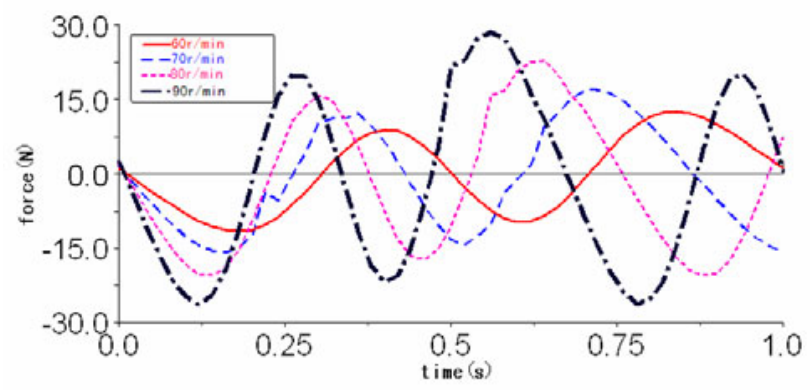

Fig. 7. The reaction of crankshaft bearing on Y axis direction 


\subsection{The Analysis of Forces of Links to Cutting Blade}

The cutting blade and the slider of cutting mechanism was the same component, because there was a gap between the slider and guide, and a vertical direction force which would cause the blade slightly deformed in motion occurs existed in the forces of the linkage driving the slider movement, it caused the hypotenuse phenomenon of cutting lotus root.

When the crank speed was 60 90r/min, the forces of connecting rod on the slice knife in $\mathrm{X}$ and $\mathrm{y}$ direction, obtained from dynamics simulation on the virtual prototype, as shown in Figure 8 9.

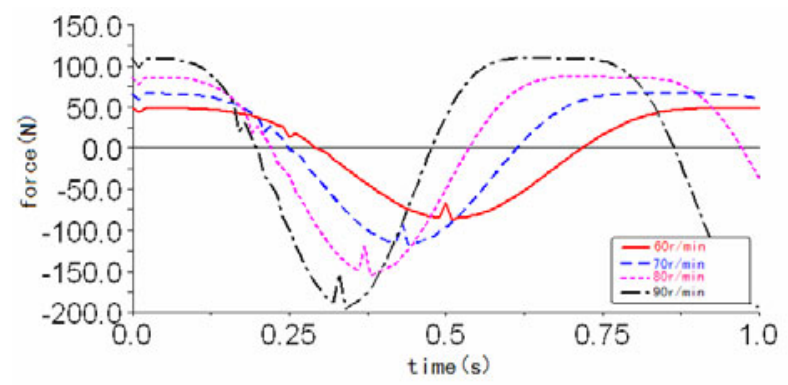

Fig. 8. The curve of horizontal component force

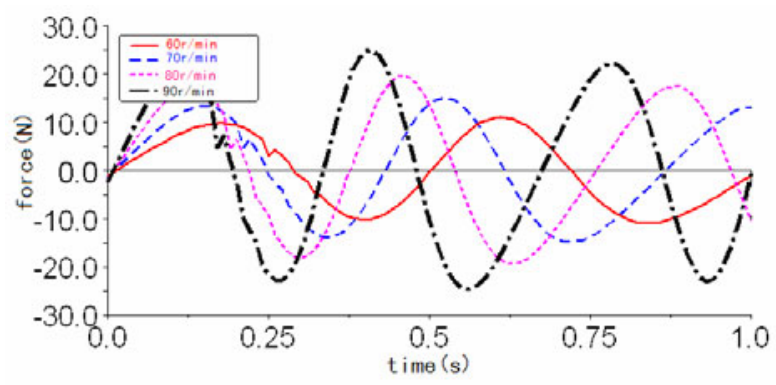

Fig. 9. The curve of vertical component force

Figure 8 reflected that the horizontal force of connecting rod on the slice knife increased with the speed of crank increased. The cutting of lotus root facilitated, for the change of the horizontal force was stability, during the time of 0 s to $0.2 \mathrm{~s}$. Figure 9 reflected the changes of the vertical force. The conclusion obtained from figure 9 was that it was more detrimental to guarantee the cutting quality of lotus root, for the vertical force became bigger with the crank speed increased.

\subsection{The Dynamics Simulation Analysis of Slicer Machine}

Due to the imbalance inertial force existed in the cutting mechanism, so there was a certain vibration at work in the slicing machine, and the vibration in horizontal and vertical at the work surface had a direct impaction on the quality of lotus root cutting, therefore, it was necessary to study the dynamic characteristics of the slicer machine. 
The acceleration curve in $\mathrm{X}, \mathrm{Y}$ direction of the work surface in the crank speed 70r/min shown in Figure 10, 11. The vibration in the $\mathrm{X}$ direction was much bigger than the $\mathrm{Y}$ direction from the chart, further descript that the imbalance inertial force in the $\mathrm{x}$ direction was the main reason caused the vibration of slicer surface.

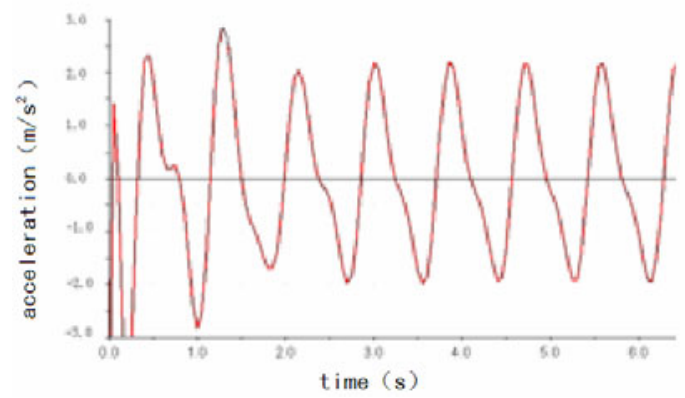

Fig. 10. The acceleration curve of workbench on $\mathrm{X}$ axis direction

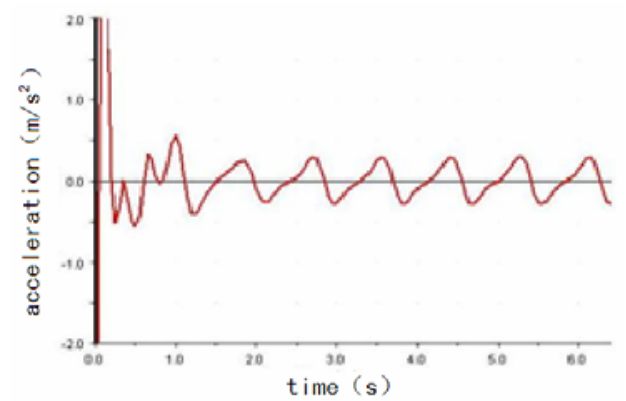

Fig. 11. The acceleration curve of workbench on $\mathrm{Y}$ axis direction

\section{Conclusion}

1. The best cutting time of lotus root was $0.15 \mathrm{~s} \sim 0.25 \mathrm{~s}$ obtained from the kinematics simulation of the cutting mechanism. During that time, the cutting blade reached the speed needed by cutting lotus root and the acceleration was relatively stable, it was in favor of lotus root cutting. The simulation results provided the basis for determine of the initial position of the blade cutting points.

2. For the reaction force in the horizontal direction of Crank bearing spider was much greater than the vertical in the respect of the influence of the system vibration, the reaction force in the $\mathrm{X}$ direction of the crank bearing spider was one of the major causes caused the vibration of slicing machine surface, which had been verified in the dynamics simulation.

3. The main reason caused the hypotenuse of lotus root was that the vertical force of connecting rod to the blade in the cutting process. The stress situation of the horizontal and vertical direction at the hinge point was obtained by the stress analysis at the hinge point attached connecting rod and blade, as provided a basis for optimized the vertical force at the hinge point next. 


\section{References}

1. Wei, B.: Studies on slicing techniques and material characteristic of lotus root. D. Jiangsu University (2006)

2. Yang, J., Yang, X., Zhou, Y.: Virtual simulation test of the Small Tillage Machine Vibration damping handle. J. Transactions of the Chinese society for agricultural machinery 37(11), 188-192 (2006)

3. Wei dong, P.: Flexible multibody dynamic simulation. D. The University of Iowa (1998)

4. Lin, J., Zhang, B., Fu, W., et al.: Research of Dummy Simulation on Kinematics and Dynamics of Engine with New Type of Multi-link Mechanism. J. Transactions of CSICE 24(6), 565-568 (2006)

5. Hu, M., Deng, Z., Gao, H., et al.: Dynamic modeling and simulation analysis based ADMAS of the six-wheeled lunar rover. J. Journal Of Harbin Institute Of Technology 39(1), 565-568 (2007)

6. Wei, E.: The Simulation and Optimization on the New Slicing Machine of Lotus Root Based on Virtual Prototype Technology. D. Jiangsu University (2008)

7. Kong, Z.: Design of Cotton Transplanter Based on Virtual Prototype. D. Shandong University Of Technology (2006)

8. An, W., Chen, H., Chen, X., et al.: Dynamics simulation research based on virtual prototype of diesel engine. J.Computer simulation 23(10), 231-235 (2006)

9. Yu, Y.: The Application of Virtual Prototyping Technology on the Dynamic Analysis of Portal Machinery.D. TONGJI University (2006) 